\title{
DEBATE: A CINCUENTA AÑOS DEL TRIUNFO DE SALVADOR ALLENDE, ¿CUÁL ES EL LEGADO PARA EL CHILE ACTUAL?
}

Clarisa Hardy Raskovan, Rodrigo Mundaca Cabrera, Carlos Ruiz Encina y Camila Vallejo Dowling 


\title{
DEBATE: A CINCUENTA AÑOS DEL TRIUNFO DE SALVADOR ALLENDE, ¿CUÁL ES EL LEGADO PARA EL CHILE ACTUAL? 1
}

\author{
Clarisa Hardy Raskovan, Rodrigo Mundaca Cabrera, Carlos Ruiz, Encina y \\ Camila Vallejo Dowling
}

Modera: Jennifer Abate Cruces

Jennifer Abate: "A cincuenta años del triunfo de Salvador Allende: ¿cuál es el legado para el Chile actual?" es la conversación de hoy, la tercera y última de este ciclo. Presentaré a quiénes dialogarán en esta instancia.

Está con nosotros Carlos Ruiz, sociólogo y académico del Departamento de Sociología de la Facultad de Ciencias Sociales de la Universidad de Chile, del cual fue director entre 2014 y 2018. También es presidente de la Fundación Nodo XXI. Entre sus libros se cuentan Los chilenos bajo el neoliberalismo: clases y conflicto social, en coautoría con Giorgio Boccardo; De nuevo la sociedad; La política en el neoliberalismo: experiencias latinoamericanas; y Octubre chileno: la irrupción de un nuevo pueblo.

También está con nosotros Clarisa Hardy, sicóloga de la Universidad de Chile y diplomada en Antropología Social en la Universidad de Oxford, Inglaterra. Es experta en políticas sociales, fue ministra de Planificación en el primer gobierno de la presidenta Michelle Bachelet y ha sido consultora de gobiernos en Argentina, Guatemala, México, Paraguay, Perú, República Dominicana y Uruguay, así como en varios organismos internacionales como el PNUd, Unicef, Oit, BID y CePAL, entre otros. Es la presidenta del Instituto Igualdad. Entre sus libros se cuentan Organizarse para vivir: pobreza urbana y organización popular, Derechos ciudadanos, en coautoría con Pablo Morris; y Estratificación social en América Latina: retos de cohesión social.

Recibimos también a Rodrigo Mundaca, ingeniero agrónomo de la Universidad de Chile y activista por el derecho al agua como bien público y derecho humano esencial. Es vocero nacional del Movimiento de Defensa por el Acceso al Agua, la Tierra y la Protección al Medio Ambiente, Modatima. Por su activismo en este campo fue galardonado en 2019 con el Premio Internacional de Derechos Humanos de Núremberg. Es autor de numerosos artículos sobre temas medioambientales y

1. Este debate se realizó el martes 22 de septiembre de 2020, a través de una transmisión en línea de la Vicerrectoría de Extensión y Comunicaciones de la Universidad de Chile. 
en 2015 publicó La privatización de las aguas en Chile: causas y resistencias, que da cuenta del problema del acceso al agua en el contexto de su privatización en Chile.

Finalmente, agradecemos la presencia de la diputada Camila Vallejo, geógrafa de la Universidad de Chile y diputada de la República de Chile por el distrito 12. Fue presidenta de la Federación de Estudiantes de la Universidad de Chile entre 2010 y 2011, lo que la convirtió en la primera mujer en ocupar dicho cargo y una de las principales líderes de la movilización estudiantil de 2011. En la Cámara de Diputados y Diputadas integra las comisiones permanentes de Educación y Mujeres y Equidad de Género. Entre otros reconocimientos, ha sido distinguida como Miembro Honorífico de la Universidad de La Plata, en Argentina, y como Líder Estudiantil Mundial en la Defensa de los Derechos Humanos 2011 por Amnistía Internacional.

Comencemos con esto: ¿cuál es, a su juicio, el mayor legado del triunfo de Salvador Allende y del gobierno de la UP? Parte, en esta vuelta, el académico Carlos Ruiz.

Carlos Ruiz: muy buenas tardes, les agradezco mucho la invitación. Me siento quizás como en casa en la Universidad de Chile, pero siempre es un agrado estar aquí conversando. Saludo al resto del panel. Es difícil decir cuál es el mayor legado, pero voy a apuntar a uno que me parece particularmente relevante en función de los desafíos actuales. Tiene que ver con que la forma de construcción de la UP intenta resolver un dilema que hoy vuelve a repetirse, el de las alianzas políticas y las luchas sociales. La experiencia popular es extremadamente rica en su relación entre las luchas políticas y las sociales. El pueblo chileno enfrenta el sistema neoliberal más poderoso de América Latina, resultado del giro capitalista que produce un nuevo mapa de luchas sociales. Ahí vuelven a resonar estos dilemas de conformación política de una diversidad muy prolífica de luchas populares, como las que hemos visto surgir desde el 18-O.

La noción de pueblo apela a la conciencia social, generalmente como un enfrentamiento a una oligarquía entendida en la vieja acepción de "poder de pocos", a una oligarquía del abuso, de ahí la idea de que "no son treinta pesos, son treinta años". Habla de una élite de abuso postPinochet. Así, el pueblo aparece como un sujeto histórico compuesto por una heterogeneidad de grupos sociales y clases, y la articulación de esas luchas populares es el complejo reto para elegir una izquierda. La sociedad chilena difiere de la que era propia en la UP, pero muchos dilemas se reiteran y hoy desbordan las alianzas políticas. La UP remite a una acción de la mayor unidad política y de la mayor unidad social que alcanza la historia chilena. Su llegada al poder, en 1970, y el golpe militar son quizás sus hitos más visibles, pero su formación como alianza social y política se entiende menos, y ahí me parece que 
vale la pena poner el ojo. Su formación no es tanto un lugar de llegada, un punto de partida del gobierno, sino que es el punto de llegada de un largo proceso de acción, donde quiero puntualizar tres cuestiones.

Primero, la fundación del gobierno de la UP es posible gracias a un programa común del que hoy se dista mucho, inmersos como estamos en lo que hoy se conoce como políticas sectoriales y recetas específicas, propias de una mirada neoliberal que se impuso en la transición. El programa de la UP, con sus luces y sombras, consistía en una estrategia de cambio y una lectura de la sociedad chilena. Su formación es de naturaleza estratégica, y es ahí donde también está su problema. Es un hito que interpela a la actual reducción a dilemas administrativos. Segundo, su formación también tuvo diferencias entre partidos y dentro de los partidos —los socialistas y comunistas tenían grandes enfrentamientos-, pero el mérito de la UP fue procesar esas diferencias sin negarlas. Los debates fueron duros antes de llegar al gobierno, pero estaban basados en juicios políticos y no en intereses burocráticos y personales. Fue un debate muy interesante que concitó el interés internacional. En tercer lugar, la formación de la UP supuso articular fuerzas políticas y sociales, una diversidad de clases. La unidad de sus partidos en las organizaciones sociales y una UP que estaba presente tanto en la sociedad como en el Estado es una combinación que también se ha olvidado hoy.

Esa izquierda entendía la acción social y la política de manera directa, pero lo cierto - $\mathrm{y}$ eso es innegable- es que la UP era depositaria de una cultura de izquierda con una muy alta conciencia de los procesos que anidaban en la sociedad, por eso es que su herencia repone hoy el dilema de las alianzas políticas no como un ajedrez burocrático, sino que ante las condiciones sociales y las disyuntivas que están abiertas. El levamiento popular hoy vuelve a enfrentar un desafío semejante ante un nuevo pueblo — yo le he llamado un nuevo pueblo- que emerge de la nueva mutación neoliberal y que surge con nuevas fuerzas y nuevas identidades. Las nuevas fuerzas políticas, en particular, diría yo, el Frente Amplio, errarían al ignorar el proceso de la UP, aunque también errarían llegando al otro extremo, a apelar a una continuidad mecánica de la UP y a una cuestión solamente identitaria, como ocurre con otra izquierda. Creo que en ese dilema nos movemos y creo que hay que ir de la mera reivindicación de la UP al examen de su formación como alianza social, como alianza política, para anclar el homenaje en las urgencias del presente. Gracias.

Jennifer Abate: gracias, Carlos. Hace poco conversábamos con Jorge Arrate sobre esto en el programa Palabra Pública en Radio Universidad de Chile. Jorge ponía el acento en que, por su fin trágico, se tiende a hablar mucho del fin de la UP y se piensa menos en las condiciones y visiones que hicieron que triunfara en un momento 
determinado. Clarisa, ¿cuáles son los legados de Salvador Allende mirados hoy, a cincuenta años?

Clarisa Hardy: en primer lugar, muchas gracias por la invitación y la posibilidad de compartir con Carlos y Rodrigo ${ }^{2}$. Para esta conversación me pongo en una perspectiva distinta. Me parece interesante lo que planta Carlos, pero, por un asunto generacional, hago una aproximación distinta. A diferencia de ustedes, yo era una persona adulta joven, activa, votaba en esa época. Desde ahí es cómo elaboro mi respuesta y me planteo en dos niveles. El primero, analizando la figura de Salvador Allende, que nos remite a la construcción de liderazgos, muy en la línea de lo que dice Carlos. La otra dimensión refiere a las lecciones que nos deja el fenómeno de la UP y su gobierno como retos democráticos, compartiendo lo que dijo Carlos, en un escenario distinto en cuanto al rol y peso de los partidos.

Respecto de Salvador Allende, él combinaba dos elementos escasos de encontrar en la actual conformación de los liderazgos políticos. Liderazgo político no es cuán popular es una persona, sino cuánto es capaz de asumir la conducción de un proyecto para expresar a grandes mayorías. En su caso, era un liderazgo fundado en ideas, tenía un proyecto de país, un proyecto de sociedad. Hoy en día las ideas han sido sustituidas por cuñas, los actuales liderazgos mediáticos sustituyen las ideas por cuñas y estamos llenos de declaraciones y titulares que se repiten sin ninguna sustancia. En esa época, detrás del titular venía la sustancia. Además, tenía otro rasgo que se le pide a los liderazgos, "tener calle". El de Salvador Allende fue un liderazgo construido con distintos actores de la sociedad chilena de entonces. No nos olvidemos de que tuvo cuatro campañas presidenciales que le permitieron recorrer el país completo y hablar, pero no era hablar en un puerta a puerta o a través de panfletos, sino sentándose a conversar. La construcción de las ideas estaba anclada en las vidas cotidianas de las personas.

Más allá de los rasgos de ese liderazgo hoy tan ausentes, y observando el desarrollo del gobierno de la UP, los obstáculos que enfrentó, extraigo tres lecciones que son muy pertinentes para el debate actual. Soy parte de una generación de las izquierdas que creyó en la democracia con apellidos, estaba la democracia burguesa y la democracia proletaria y, por lo tanto, era parte de un gran debate sobre las distintas vías para hacer posible la transformación social o la revolución. El hito más importante que Allende expuso ante el mundo y en Chile fue plantearse esa transformación desde los instrumentos de la institucionalidad democrática. Pero Allende convivió con mi generación, que tensionó permanentemente esa apuesta.

2. La diputada Camila Vallejo se sumó más tarde a la conversación pues se encontraba cumpliendo sus deberes en la Cámara de Diputados y Diputadas. 
Este debate estaba presente y hubo muchas dificultades y tensiones en el campo de la izquierda. La izquierda tenía una retórica cuestionadora de la democracia burguesa, liberal, pero la UP nunca violentó la institucionalidad democrática más allá del radicalismo verbal. En cambio, la derecha usaba una retórica democrática, como nos lo recordó Verónica en el conversatorio pasado, pero una práctica - como se demostraría - antidemocrática. Estos hechos de la historia política también los hizo presente en medio de la UP un intelectual francés, Alain Joxe, quien hizo un análisis de la realidad chilena y demostró que cada vez que se amenazaba el orden social, las oligarquías intervenían de la mano de las Fuerzas Armadas. Esta izquierda de radicalismo verbal, que cuestionaba la así llamada democracia burguesa, desconsideraba el fenómeno del golpismo. Había antecedentes golpistas y antidemocráticos que la derecha usó a lo largo de la historia.

Mis lecciones a partir de esta evidencia. Cuando uno se propone hacer transformaciones estructurales, con convicciones democráticas, requiere contar con la fuerza social y política que lo hagan posible, esa es la primera lección. Allende ganó con 34 por ciento del electorado, subió a 44 por ciento en las parlamentarias. Contaba con la fuerza de los trabajadores organizados sindicalmente, que eran una parte de la población trabajadora, pero no olvidemos la alta informalidad, la pequeña y mediana propiedad; contaba con el apoyo campesino; contaba con el estudiantado, pero recordemos que los estudiantes que llegaban a la universidad eran de la élite. Aunque en su programa había una extensión de becas masivas para el acceso universitario, la educación era muy segregada y pocos podían terminar sus estudios para llegar a la educación superior; nos eran esquivas las capas medias.

La segunda lección que yo extraigo de lo anterior es que emprender transformaciones sociales con estas exigencias requiere el buen funcionamiento de la economía. Parte de cierta adhesión que se fue perdiendo se produjo por los problemas de la inflación, desabastecimiento, producción y distribución. Si bien intencionalmente promovidos por la derecha y financiados por Estados Unidos, como ha sido desclasificado y es de público conocimiento, pero también fundados en errores de gestión y políticas de gobierno que minaron parte de la adhesión social. Hay muchos estudios que demuestran que la insatisfacción de expectativas, la frustración por no poder satisfacer las necesidades genera problemas sociales, sobre todo cuando existía circulante por la mejora importante de los salarios de ese entonces.

Y la tercera tiene que ver con la violencia. Hoy me parece que hay un pésimo debate sobre lo que significa la violencia, no conocemos de las izquierdas actuales planteamientos que se acerquen en lo más mínimo a la legitimación de la violencia como sí existía entonces, y una derecha golpista que no ocultaba sus esfuerzos de desestabilización. Hemos aprendido que la democracia se sana con más democracia, 
con la adhesión a las reglas de la democracia y que ella es la base para posibilitar y legitimar las transformaciones.

Jennifer Abate: muchas gracias, Clarisa. Tú hacías un punto sobre el liderazgo que viene de la calle. Rodrigo Mundaca viene de ese mundo, no de las cúpulas, sino del trabajo en el territorio. Rodrigo, ¿cuáles son los principales legados hoy, a cincuenta años del triunfo de Salvador Allende y de la UP?

Rodrigo Mundaca: primero, doy las gracias por esta invitación, gracias a los que me antecedieron, a Clarisa, que no tenía el gusto de conocerla, y a Carlos, con quien últimamente hemos coincidido en dos, tres paneles de debates: hemos estado debatiendo fuertemente y eso nos ha ayudado muchísimo. Eduardo Mundaca era mi padre, era un furibundo allendista, funcionario del Instituto Nacional de Estadísticas, trabajó con Arsenio Poupin directamente y participó del proceso de reforma agraria en Cauquenes. Yo era pequeño y acompañaba a mi padre en esos autos que llegaban de Checoslovaquia en ese tiempo, y andábamos en esos jeeps para arriba y para abajo. Lo acompañé a muchas acciones de preparación de todo tipo, pensando siempre que el sabotaje que haría la derecha tendría rasgos como los que tuvo el 11 de septiembre de 1973. Tempranamente, me tocó hacer lo que se tiene que hacer en casa después de que el viejo no estuvo después del 11 de septiembre. Voy a recordar una cita de Lucho Corvalán: "hubo que esconder aquello por si las moscas". Lo digo como lo dijo alguna vez Lucho Corvalán por Carrizal, a veces hay que guardar algunas cosas por si las moscas. Me tocó desde muy chico cumplir esa misión, por lo tanto, me siento muy orgulloso de lo que hizo el Lalo, mi padre.

Estuve trabajando en las cuarenta medidas iniciales del gobierno popular y estuve leyendo intensamente e intenté focalizar en esas medidas, que están tremendamente vigentes hoy. Yo creo que Allende siempre fue un tipo adelantado e incomprendido, fue un revolucionario de tomo y lomo, más allá de la crítica pequeña, y demostró coherencia, a diferencia de otros presidentes de América Latina que toman aviones y se fugan; defendió con la fuerza material el gobierno democráticamente construido y creo que ese es un legado tremendamente importante para las generaciones que combatieron la dictadura y para las posteriores, incluso aquellas que encabezaron la rebelión popular del 18 de octubre en adelante. Vi muchas veces la figura de Allende en los despliegues territoriales del 18 de octubre en adelante, con la gesta popular, con la fuerza material, y creo que no tenemos que ocultarlo y tampoco sentirnos avergonzados de aquello quienes pensamos que esa era la vía para defender el gobierno popular.

A propósito de las cuarenta medidas, me llamó muchísimo la atención una formulación en el inicio de la UP, cuando dice, literal: “quiero asegurar un crecimiento 
rápido y descentralizado, tendiente a desarrollar al máximo las fuerzas productivas, procurando el óptimo aprovechamiento de los recursos humanos, naturales, financieros y técnicos disponibles, a fin de activar la fuerza productiva del trabajo y de satisfacer tanto las exigencias del desarrollo independiente de la economía como las necesidades y aspiraciones de la población trabajadora compatibles con una vida digna y humana". Me llamó mucho, muchísimo la atención esa declaración. Allende, en ese periodo del 70,71,73, colocaba al centro del crecimiento económico la vida digna y humana y, esto me decía un amigo, con esa intención, al poner en el centro de su preocupación la vida digna y humana, puso al centro de la preocupación el desarrollo sustentable.

Yo siempre cito a un geógrafo británico que me gusta mucho, que plantea que en América Latina y en Chile, en particular, hay un patrón de acumulación por desposesión expresado de forma brutal en bienes naturales comunes, porque finalmente este patrón de exportación se define por la depredación de los recursos naturales. Allende, ya en la década del setenta, a propósito de su gobierno, ponía en el centro de su preocupación la vida digna y humana.

Creo que ese elemento, construido o declarado metafóricamente en la década del setenta, hoy tiene una vigencia tremenda cuando tenemos cinco zonas de sacrificio, 29 termoeléctricas, cuando tenemos un modelo forestal fraguado en dictadura, en el año 74, y que invariablemente los gobiernos, desde el año noventa en adelante, prorrogaron sucesivamente: el Decreto Ley Forestal 701, fraguado en dictadura, que permitió la enajenación inicial de dos millones de hectáreas de asentamientos mapuche para construir este modelo forestal que se construye desde el erario público, es decir, se construye con recursos del Estado. Ahí nada tiene que ver con la vida digna. Este monopolio forestal en manos de Matte y Angelini es una de las luchas del pueblo mapuche; nada tiene que ver este modelo forestal con eso que pensó, anheló Salvador Allende.

Creo que es importante mencionar tres cosas más. La profundización de la reforma agraria, diferente del proyecto de Eduardo Frei Montalva y de la "reforma del macetero" de Alessandri. La reforma de Frei Montalva mantuvo la propiedad al crear los asentamientos, o sea, la propiedad se mantuvo invariable. En cambio, la reforma agraria de Salvador Allende tiene una impronta tremendamente importante, que tiene que ver con la cooperativización en el campo, con ponerle límites a la propiedad de la tierra. Cuán distinto ese proceso del que comenzó en 1973: la contrarreforma agraria significó la devolución de la tierra a sus antiguos dueños, la mantención de un tercio, solamente, de la propiedad reformada, y el tercio de la propiedad restante se la entregó a los funcionarios de la dictadura. Cuán distinto es aquello respecto de hoy, cuando el latifundio existe y existen todavía condiciones de inquilinaje en sectores rurales del país. Ese sueño, ese anhelo de Salvador Allende 
en los mil días, se ha visto completamente truncado, la agricultura en Chile es un capital económico que da beneficios a los dueños de la tierra y del agua. Creo que la nacionalización del cobre ponía la impronta en el ejercicio popular, los bienes en las manos del pueblo chileno.

Concluyo con un elemento enunciado en una de las cuarenta medidas, que era servicios básicos para todos. Hablaba de casa, de luz, de agua potable para todos. Hoy estamos con un régimen liderado por Piñera, que se niega a aprobar una ley que tenía que ver precisamente con garantizar los servicios básicos en esta pandemia que estamos viviendo. Hoy, cuando son millones los niños que tienen que estudiar vía WhatsApp, conectados a Internet, cuando son miles de personas las que necesitan servicios básicos para poder refugiarse en esta crisis de envergadura que estamos enfrentando, pienso en cuán profundo caló el neoliberalismo en Chile, fraguado en la dictadura, pero cuán profundo caló el neoliberalismo del noventa en adelante, y qué distinto era al anhelo que tuvo Salvador Allende y al programa de gobierno que estuvo en su origen.

Jennifer Abate: gracias, Rodrigo. Bienvenida, diputada Camila Vallejo.

Camila Vallejo: hola, buenas tardes.

Jennifer Abate: gracias por incorporarse. Estamos en una conversación inicial sobre los legados del triunfo de Salvador Allende y el gobierno de la UP.

Camila Vallejo: muchas gracias por la invitación a la Universidad de Chile, mi casa de estudios, le tengo mucho cariño y afecto, más en este contexto tan importante, en un año decisivo, ad portas del plebiscito de octubre y con el aniversario de la UP. Saludo a Clarisa, Carlos y Rodrigo. Yo no viví la UP, nací el año 88, mis conocimientos sobre la UP son de familia, de libros y de compañeros y compañeras militantes y no militantes que sí vivieron ese proceso, con sus momentos alegres y esperanzadores, y después la dictadura militar, con las atrocidades más complejas como la persecución, detención, desaparición y torturas.

A mí me cuesta ver cuáles fueron los principales errores del gobierno de la UP. Obviamente, no me gusta centrarme en qué cosas debieron hacerse mejor, qué cosas pudieron haberse evitado; me cuesta entrar en ese juicio crítico de la UP y su primer año de gobierno. Más bien, me gusta recoger los elementos positivos que nos permiten hoy sentar bases para un proyecto en el contexto actual. Creo que lo principal del gobierno de la UP, más allá del liderazgo de Salvador Allende, que es incuestionable y totalmente decidor de lo que fue el proceso y construcción de alianzas, es que había un proceso de acumulación previo que llevó a la UP al 
poder. Uno no puede ver a la UP sin ver el interior de la UP, los partidos que se fueron fortaleciendo, la capacidad de construcción. Hubo un proceso estudiantil más allá del 68, reflejo de un contexto donde había capacidad para hacer una lectura profunda de las desigualdades y, a partir de ese diagnóstico, construir un proyecto más allá de lo programático.

Si uno ve las cuarenta medidas, hay un hilo conductor, que es el socialismo, y había una mirada estratégica sobre cómo avanzar hacia ese proyecto socialista. Impresiona que en ese entonces no era solo el Partido Socialista o el Partido Comunista los que hablaban de socialismo, sino que incluso desde la Democracia Cristiana se hablaba de un proyecto revolucionario hacia el socialismo. Había capacidad de construir un proyecto que trascendiera un gobierno, sostenido con partidos políticos con base social y política, bien institucionalizado, pero que además logró hacer de la participación popular un eje estructurante del proceso. Hoy vemos muchos discursos que aseguran que el pueblo necesita participación y escuchamos poco sobre cómo llevarlo a la práctica. Un eje del legado del proyecto de la UP fue la capacidad de que el pueblo no solamente se sintiese protagonista, sino que fuese protagonista del proceso de transformación, con sindicatos, juntas de vecinos, organizaciones estudiantiles, con las personas que no se sentían organizadas, es decir, no estaba solamente el programa y el proyecto enclaustrado en el Congreso y en el palacio de La Moneda como instituciones responsables de lograr el cambio, sino que había un proceso asentado en toda la base popular; la gran mayoría, todos se sentían responsables y protagonistas de ese cambio. Había una sensación de conciencia de clase que no solo estaba en los partidos y su capacidad de armar alianzas, sino que también en las bases populares.

Una cuestión que sintetiza muy bien eso es el discurso de Allende en la madrugada del 5 de septiembre, después del resultado electoral: "El programa de la UP fue la bandera del primer gobierno auténticamente democrático, popular, nacional y revolucionario de la historia de Chile. Solo quiero señalar ante la historia el hecho trascendental de que ustedes — haciendo referencia al pueblo de Chilelo han realizado derrotando la soberbia del dinero, la presión y la amenaza, la información deformada, la campaña del terror, de la insidia, de la maldad. Cuando el pueblo ha sido capaz de esto será capaz de comprender que solo trabajando más y produciendo más podemos hacer que Chile progrese. La revolución no implica destruir, no implica arrasar, sino edificar".

En este discurso hay elementos centrales, como el proyecto popular nacional revolucionario y democrático, por todos conocido; la vía chilena al socialismo está dentro de un proceso democrático, pero tremendamente revolucionario, y una de las cosas que lo hace muy revolucionario es el rol trascendental del pueblo de Chile, que tiene un nivel de conciencia tal, que a pesar del dinero, las presiones, amenazas, 
la desinformación, la campaña del terror, la insidia, etcétera, logró entender la importancia de seguir adelante con este proyecto. Este estaba muy centrado no solo en cómo superábamos el capitalismo, sino en cómo construíamos y edificábamos un proyecto de socialismo. Eso movilizó a mucha gente y la llevó a trabajar duramente. Esto puede sonar un cliché y caer en el discurso identitario de lo que fue, pero más que un proyecto fracasado, la UP fue un proyecto interrumpido, y luego de la interrupción, con el quiebre democrático, la dictadura y lo que vino después, el plebiscito trajo un poquito de esperanza, pero nunca logró interpretar, creo yo, lo que logró interpretar el pueblo en el proyecto de la UP. El proyecto de la UP es un proyecto interrumpido, mas no fracasado. Eso no significa que nosotros tomemos el proyecto de la UP y le demos continuidad y lo traslademos al presente. Creo que, como partidos, estamos alejados de la realidad que teníamos antes, pero a nivel de participación popular y de potencial, las movilizaciones son lo importante y clave para este nuevo proyecto que necesitamos para el Chile del siglo XXI, que tiene que estar pensado para un tipo de socialismo a la chilena entendiendo el contexto actual que tenemos y que hay que asimilar en este Chile neoliberal.

Jennifer Abate: la diputada Vallejo señalaba que no es posible tomar el proyecto de la Unidad Popular y traspasarlo a nuestros días. Estamos en un momento de mucho cambio, efervescencia, Carlos lo cuenta en su libro: es un Chile distinto, pero si bien la política ha corrido los límites de lo posible, probablemente gracias a las luchas populares, quedan desafíos. ¿Cuáles son esos desafíos, a su juicio, en Chile actualmente? ¿Cuál sería la propuesta programática para un desarrollo realmente inclusivo para nuestro país, que permita superar las brechas? Esta es la pregunta para ustedes: ¿cuáles son los temas pendientes en lo que deberíamos avanzar en el Chile de hoy? Parte Carlos Ruiz.

Carlos Ruiz: vamos a ver si puedo agarrar todo eso, está difícil. Tengo la impresión de que estamos en un contexto que se viene agudizando hace tiempo, con mucho distanciamiento entre sociedad y política; hace mucho que no hay grandes mayorías políticas. Ya el gobierno de Bachelet tenía un cuarto de los votos y vemos un deterioro, una crisis de legitimación incluso en las instituciones, y eso es lo que hace que la movilización tienda al desborde de los políticos; es una movilización sin banderas de partidos ni colores, solo es una bandera negra y es algo que nos interpela como izquierda, como Frente Amplio, que es construir una alianza para salir de estos gobiernos de derecha. Estamos interpelados con un taxímetro. Tenemos que responder y abrir un debate. Hay idearios presentes en la UP que fuimos perdiendo en el camino. Así, por ejemplo, nos cuesta lidiar con las banderas de lo individual. Nuestra forma de adherir a las banderas de la igualdad fue sacrificando la libertad 
durante el siglo XX, y ahí entra el discurso neoliberal, donde lo que prima es la responsabilidad social y es ahí donde nosotros tenemos que entrar a recuperar una interpelación gigantesca, recuperar los idearios de libertad e igualdad.

Creo que Rodrigo lo mencionó, la idea del socialismo como una especie de competencia contra el neoliberalismo del crecimiento económico que descansaba en toneladas de producción de acero. Por el contrario, recuperar un socialismo vinculado al individuo y su noción de soberanía, que siempre fue muy particular del proceso popular latinoamericano. Estábamos tan lejos de Dios y tan cerca de Estados Unidos, como dicen los mexicanos.

Para el plebiscito de 1988, la idea del conflicto entre el Estado y el mercado se dibujaba en el campo de los ideales de libertad e igualdad: la libertad la tomaba la derecha, la libertad de educación y etcétera. Pero, desde 2006 y 2011, ese conflicto entre Estado y mercado se fue desdibujando crecientemente en la medida en que se fue fraguando una élite que con la izquierda jugaba al Estado y con la derecha al mercado. Fueron apareciendo los Pickering. ¿Quién es [Guillermo] Pickering? ¿El Estado o el mercado? Las dos cosas.

Durante la UP había mucha conciencia, en general, en todos los partidos, de que el proceso que se vivía requería un protagonismo desde el Estado y desde la sociedad, y eso nutría debates. Fueron famosos esos debates y concitaban la atención internacional, todos miraran esta experiencia. Ese equilibro se fue perdiendo. No es casual que termináramos en unos partidos que no resuelven la ecuación entre alianzas políticas y necesidades sociales, estoy de acuerdo con la manera en que lo dibujaba Camila. Yo tampoco viví el periodo como protagonista, pero creo que una de las lecciones, de los legados que nos interpela de esa epopeya, es la vinculación permanente entre esas dos dimensiones. No alcanzo a referirme a otro punto que tocó Clarisa: que la UP nos deja una interpelación tremenda sobre cómo proteger el proceso democrático.

Jennifer Abate: gracias, Carlos. Clarisa Hardy.

Clarisa Hardy: cuando yo dije que lo miraba de otra manera porque fui partícipe, no lo hice para deslegitimar las posturas de quienes no lo vivieron, obviamente por razones de edad. Solo que me pone en una perspectiva distinta porque siento, de alguna manera, la responsabilidad de las decisiones que se adoptaron y que terminaron trágicamente en muertes. Esa experiencia te interpela muy directamente, pues participaste en lo que ocurrió en sus aspectos muy positivos, pero también en los desenlaces, que fueron brutales. Siento la responsabilidad política de hacer este recuento que hice al inicio. 
Y si mencioné los retos de hoy es porque estamos en un punto de inflexión inesperado. El proceso constituyente que se abre ahora es una oportunidad que no habíamos tenido para plantearnos el nuevo pacto político con una Constitución. Y al recibir esta invitación recordé, como mencionaba Rodrigo, que en el programa de la UP se contemplaba una nueva Constitución. Se estimaba entonces que, a cincuenta años de la de 1925, el texto que iba a cumplir medio siglo ya no reflejaba la realidad de la época. El año 1972 se constituyó una comisión nombrada por Allende para elaborar la propuesta constitucional — no puedo dejar de mencionar que en ella no había ninguna mujer, a diferencia de la actual conformación paritariapero la metodología participativa para su trabajo tenía mucho que ver con lo que han mencionado Carlos y Camila en sus intervenciones, reflejaba esta articulación permanente entre la política y la sociedad, involucrando a distintas organizaciones. $\mathrm{Al}$ igual que la metodología que se construyó con la presidenta Bachelet para abrir una discusión constituyente, con Allende estaba planteada la idea de un documento de nueva Constitución para someterlo a la deliberación de sindicatos, escuelas, fábricas, universidades, abriendo la participación a quienes podrían contribuir a dicho texto. ¿Por qué lo menciono? Porque Carlos tiene razón: la gran deuda que tenemos hoy no es la despolitización, sino la despartidización. Pienso que ha habido una repolitización de la sociedad, lo vimos con el estallido del año pasado, se politizó la conversación ciudadana, se convirtieron las plazas y calles en verdaderos foros de conversación política, pero en un proceso de despartidización, es decir, hay un proyecto político radicado fuera de los partidos. Y el último estudio del Centro de Estudios de Conflicto y Cohesión Social (COES) muestra una situación progresiva de deterioro de la credibilidad y confiabilidad en los partidos y el Congreso. De forma sistemática y progresiva, distintos estudios muestran una creciente percepción de que los partidos reflejan intereses y no proyectos. La despartidización de la política tiene que ver con la percepción de que en los partidos no está radicada la defensa de derechos, sino que de intereses.

El proceso constituyente es la posibilidad de abrirse a dimensiones que deben estar en la agenda pública. Es precisamente este proceso el que abre la oportunidad de hacer nuevamente esta vinculación de política y sociedad, la oportunidad de repolitizar a los partidos. Tenemos la paradoja de una sociedad politizada y partidos despolitizados. Creo que la manera de repolitizarlos es con este proceso constituyente, con la deliberación democrática, colectiva y ciudadana, con estos pactos nuevos a los que tenemos que adscribir. No quisiera entrar en el detalle de cuáles deberían ser los ejes de la nueva Constitución, pero con ese texto se suscribe un nuevo pacto político. 
Jennifer Abate: muchas gracias, Clarisa. Es interesante la idea de una sociedad politizada y de partidos que se han alejado de la política. Rodrigo Mundaca, respecto a los desafíos de la política, ¿hacia dónde vamos?

Rodrigo Mundaca: es una tremenda pregunta y estaba pensando en lo que dijeron Carlos, Clarisa y Camila, que pudiéramos recuperar el principio de distribución del trabajo que fue la epopeya que encarnó los mil días de la UP. Yo era muy pequeño y mi casa estaba llena de textos. Leímos mucho ese principio sin antes haber construido esa base material. Retomo lo que dijo Salvador Allende, que incluso habló de comercio exterior, de diversificar mercados, diversificar la estructura de productos materiales exportables, habló de independencia económica, tecnológica, y si hago una síntesis de aquello, de soberanía, de recuperación de recursos naturales. Si hablo de derechos sociales, creo que ninguno de nosotros podría estar en contra de lo que simbolizó Salvador Allende, porque es lo que ha encarnado el movimiento social todo este tiempo.

Yo no tengo ninguna duda, a propósito de Clarisa y de Carlos, de que Chile atraviesa un momento político inédito, creo que octubre reflejó nítidamente el nuevo pueblo que se cansó del abuso, de la desigualdad propia del neoliberalismo chileno. Pero ese pueblo que se movilizó en las calles, en las comunidades, en todo el país, también se cansó del consenso elitario que ha habido desde principios de los noventa, cuando nos dijeron a muchos de nosotros: "váyanse para la casa porque llegaron los políticos profesionales a solucionar los problemas". Ese consenso elitario tuvo una manera de hacer política, no lo generalizo, pero sin duda hubo un contubernio entre un porcentaje importante de la casta y los dueños de los negocios. Cuando se habla de encuestas de opinión, seguramente las instituciones peor evaluadas son los políticos, el régimen parlamentario, porque ahí se fraguó un consenso elitario que menoscabó el rol de las comunidades, que miró por sobre el hombro a comunidades donde también se construye conocimiento complejo para superar el modelo de despojo en los territorios. Específicamente, donde yo vivo, en la provincia de Petorca, tenemos más del 50 por ciento de la población abastecida por camiones. Un hito de la mercantilización tiene que ver con la privatización del agua. La privatización de todos los ámbitos de la vida fue fraguada en la dictadura, pero no se entiende por qué se profundizó postnoventa. Carlos habla de Pickering, que fue presidente de Essal, empresa sanitaria del grupo Suez que provocó una crisis sanitaria en Osorno que tuvo a la población once días sin agua porque contaminaron los lechos de agua. Guillermo Pickering trabajó en el gobierno de Lagos, ese maridaje está ahí. Y en el otro lado, cómo no mencionar a Luis Mayol, intendente que estuvo implicado en el asesinato de Camilo Catrillanca y que hoy ocupa un sillón en el directorio de Aguas Andinas, la sanitaria más importante del país. 
Evidentemente, el proceso de rebelión popular del 18-O en adelante da cuenta no solo del cansancio de los abusos, de la desigualdad, de la inequidad, sino también del cansancio del consenso elitario que ha profundizado las desigualdades y soslaya el rol nuestro, de las comunidades, de los territorios, que tiene el pueblo pobre, sencillo, el pueblo que trabaja. Por eso es que es reimportante, a propósito de desafíos, el debate en torno a las cuarenta horas semanales, en torno a dignificar al trabajador, en torno a humanizar el trabajo. Cuánta presión corporativa de parte del consenso elitario por el proyecto de ley, cuanta presión corporativa ha habido por parte del consenso elitario por el tema del agua. A propósito de desafíos para que los movimientos sociales o dirigentes sociales participen en la convención constitucional, ahí hay un debate importante, porque el consenso elitario quisiera tener al movimiento social acorralado y a ellos dirigiendo el partido.

Las fortunas de Matte, Angelini, Pérez Yoma, cuya base es la privatización de los recursos comunes, son un tema que no se puede continuar soslayando en el debate público si queremos, en alguna medida, equiparar la cancha. También debemos discutir seriamente en torno al proceso de descentralización y en torno a un proceso de creación de rentas territoriales, una ley de rentas territoriales que permita humanizar la vida en las comunidades y el territorio. No es posible que las transnacionales que depredan y contaminan el medio ambiente tributen en la metrópoli y no en el territorio, y no es posible que la renta que producen los territorios se vaya a la metrópoli y no se quede en ellos. Gracias.

Jennifer Abate: muchas gracias, Rodrigo, son enormes los desafíos que planteas. Diputada Camila Vallejo.

Camila Vallejo: tenemos un proceso social en Chile que no se puede mirar desde el estallido social solamente, porque ha sido un año muy excepcional. Como decía Clarisa, llevamos ocho meses de estado de excepción y en nuestro país se han evidenciado las falencias de nuestro sistema. Esto viene desde hace rato y obviamente hay que mirarlo como un proceso de debilitamiento de por lo menos veinte años del modelo neoliberal y, junto con eso, el debilitamiento del consenso elitario del que habla Rodrigo y que comparto totalmente. Una de las cuestiones más gravitantes de la disconformidad con la política tiene que ver con su carácter clientelar. A mí me tocó asumir la diputación y era impresionante cómo la gente se acercaba con esa idea clientelar de que después de votar por un diputado o diputada venía la vuelta de mano y esa era la política. Costaba mucho, pero promovimos juntarnos, pensar un proyecto de ley; no era la costumbre. Hoy hay más interés, politización, porque las personas entienden que les impacta, impacta la Constitución en su pensión. El estallido social fue una expresión coyuntural, pero también un problema orgánico 
que se arrastraba. Los desafíos, como decía Clarisa, hay que debatirlos en modo partidario. Todos decimos que nos faltan más programas, pero cuáles son los espacios que tenemos para hablar de esos programas y de proyectos. Muy pocos, muy pocos.

De hecho, en el Congreso, lo que nos pasa, por ejemplo, es que las discusiones se quedan en los cupos de comisiones, cómo se recupera la mesa de diputados y senadores. Pero ¿cuál es nuestra agenda legislativa? ¿Cuál es nuestro proyecto como oposición? Por ejemplo — y yo lo digo de verdad, esto es real—, a veces la discusión política tiene más que ver con los intereses políticos que con lo que proponemos al país. Creo que ese es un desafío, no podemos quedarnos en eso. Recoger el legado de Luis Emilio Recabarren es sumamente relevante en el ejercicio de descentralización, en la apuesta por la transformación de los gobiernos locales. Los municipios no pueden ser agentes de la repartija de los recursos, tienen que ser también facilitadores de la participación vinculante de los ciudadanos, el ejercicio más directo que puede tener un ciudadano es a través de ese espacio. Hay que ver cómo la oposición se pone de acuerdo, cómo los partidos con vocación transformadora se ponen de acuerdo aprovechando que hoy, a pesar de la cultura neoliberal, la gente tiene más ánimo, vocación y voluntad, no solo por las ollas comunes que se levantaron por un tema de necesidad, sino que ha habido procesos — yo diría embrionarios- de una rearticulación más barrial, comunal, y eso es algo que debe tener un lugar en un proceso de cambio, en los cambios de la Constitución, de la normativa, en la mamera en que construimos un Estado solidario, un Estado garante de derechos que nos dará posibilidades de ejercicio democrático. La pregunta es cómo vamos construyendo, desde la base, los elementos de una sociedad más democrática y participativa.

Y preguntarnos qué pasa con la economía de los cuidados. La pandemia nos ha arrojado la economía de los cuidados. Lo mencionaba Rodrigo, yo amo el proyecto de las cuarenta horas no porque sea mío o porque se nos ocurrió a nosotros, sino porque es una lucha histórica. Uno de los grandes debates tiene que ver con cómo nosotros entregamos derecho al hábitat digno, y eso tiene que ver con las viviendas, con el acceso a servicios y también con el uso del tiempo para trabajos tan esenciales como el cuidado, la familia, la comunidad, el oficio. Nuestra sociedad tiene que, de alguna manera, pensar la economía en función de cómo nos cuidamos a nosotros mismos y a los otros. ¿Valoramos ese tiempo? ¿Lo hacemos un eje central del desarrollo económico? Ahí tenemos un desafío y una oportunidad más. En la década de los sesenta y en el periodo de la UP había que iniciar un proceso de industrialización, había que tener una economía sólida para financiar lo que teníamos que financiar, pero ahora tenemos que hacer avances a nivel tecnológico. Tenemos capacidad para usar mejor nuestros recursos naturales a través de la tecnología, de la descentralización, del valor agregado, de una diversificación de la matriz productiva 
para que el objeto central no sea híperexplotar nuestros recursos naturales e híperexplotar la fuerza laboral, sino que lo justo y necesario para poder financiar y sustentar lo esencial: el desarrollo integral del ser humano y vivir, obviamente, en armonía. Me quedo hasta aquí, gracias.

Jennifer Abate: muchas gracias, diputada. En honor al tiempo que tenemos, les ofrezco que terminemos con palabras al cierre de cada uno y cada una de ustedes. Partimos con Carlos Ruiz.

Carlos Ruiz: voy a tratar de tomar dos elementos que tocaron Clarisa y Camila, a propósito del proyecto de Camila que recordaba Rodrigo. Los dominados, el mundo subalterno, no tienen otra herramienta para luchar que no sea la política, y eso tenemos que transmitirlo para volver a vincularnos. Por el contrario, ellos tienen otros recursos para constreñir la política a horizontes tecnocráticos, burocráticos, y lo que hacen es cerrarla para que no procese otros sectores sociales que no caben en la política. Entonces, lo que hay es una expulsión de intereses populares del procesamiento de las instituciones políticas, y de ahí la desidentificación con esa política. Nuestro problema es cambiar el sentido social de la política, ensanchar sus horizontes y revincular ese elemento; no tenemos otra salida. Por eso la adhesión a la democracia es una ganancia para nosotros.

Me quiero referir brevemente al proyecto de Camila. Yo lo he planteado, por ahí en un debate que tuve en el CEP: una de las cuestiones más complejas que ha instalado el neoliberalismo es la generación de nuevas fuentes de contradicción y de explotación. Eso tiene que ver, en gran parte, con una especie de deslocalización del trabajo que rompe la oficina, rompe las fábricas y se desplaza y destruye cualquier espacio, y eso empieza a cubrir a cada vez más individuos en un espacio donde el Estado no está, donde no hay regulación, donde no hay formas de generación de interés, y eso genera nuevas formas de malestar.

Me parece que este tipo de discusiones apuntan al meollo de las contradicciones que viven los individuos en el sistema neoliberal actual, y son cuestiones que no están bien recogidas en la estadística; por ejemplo, escapan a la CASEN. El individuo no es dependiente o independiente, es las dos cosas, y no tiene problema con el Estado y el mercado porque el cheque se lo da el mercado y el Estado, le dan el 10 por ciento y al día siguiente puede ir a la protesta. Hay una situación nueva del individuo, al que la situación se le ha hecho ubicua porque puede trabajar el domingo y no tiene jornada, y ese es el que está demandando un proyecto de izquierda que tiene a la base cómo pensamos las alianzas de hoy.

Jennifer Abate: gracias, Carlos. Clarisa, palabras al cierre. 
Clarisa Hardy: mientras escuchaba a Rodrigo recordaba que hace muy pocos días se reeditaron dos libros que escribí en los ochenta con las experiencias de rearticulación del tejido social en plena dictadura y cuando se estaba instalando en Chile el proyecto neoliberal en estado químicamente puro. Son dos libros que recogieron las experiencias de organización social y las graves secuelas de la crisis del 82, en plena dictadura, donde no solo no tenías un Estado protector, sino que era un Estado que amenazaba a cualquier forma de organización, sospechaba de cada una de ellas. Fueron las organizaciones urbanas populares expresadas en la forma de ollas comunes y otro tipo de organizaciones de subsistencia.

Había una reserva de estas experiencias — que fueron parte de la UP y que es la historia de los movimientos sociales y de las organizaciones en el país—, una práctica y una memoria que se mantuvieron en dictadura, emergiendo en los años ochenta. Han transcurrido más de treinta años y esa experiencia reaparece en nuestro actual tejido social con actores distintos a los de antes, pero las mismas lógicas e iniciativas solidarias, las ollas comunes. Reaparece el sentido de pertenencia comunitaria en forma simultánea a la existencia de lógicas individualistas instalándose por más de cuarenta años, con la hegemonía de valores propia del neoliberalismo. Hoy tenemos que asumir esta contradicción. Comparto que ese es el gran reto de hoy, cómo la izquierda se recompone con mirada de siglo XXI ante estos fenómenos.

Para terminar, creo en la centralidad de las y los trabajadores, que fue la base fundacional del Partido Socialista. Pero voy a hacer una referencia particular a la concepción del trabajo. Creo que las primeras proclamas feministas que escuché, sin intelectuales o movimientos feministas levantándolas en ese momento no tenían la visibilidad que han ganado después_-, fueron de las mujeres de las ollas comunes, cuando en nuestras conversaciones apareció cómo habían tomado conciencia de que el trabajo no remunerado y solidario que ellas aportaban tenía el mismo valor que el de sus parejas hombres, ahora cesantes. Por primera vez, de la práctica concreta, surgió la noción del trabajo no remunerado. Algo que ahora es común escuchar. Si en la Constitución hubiera un reconocimiento de igualdad de derechos en el trabajo remunerado y no remunerado, resolveríamos una de las grandes desigualdades presentes, así como Camila lo hizo con el proyecto de la carga horaria de trabajo y del cuidado en las mujeres. Esto le cambiaría la vida a la mitad de la población del país. La agenda de género es una que tiene que ver con una posibilidad de desarrollo distinto en Chile, no podemos tener un desarrollo sustentable e inclusivo si no incorporamos la dimensión de género en su esencia, y eso debería ser transversal en todo el debate constitucional, no solo en el institucional, sino que cruce todas las normas. El solo hecho de que la Convención Constitucional paritaria implique paridad en quienes redacten la Constitución puede influir en esta agenda constitucional feminista. 
Jennifer Abate: muchas gracias, Clarisa. Rodrigo Mundaca.

Rodrigo Mundaca: completamente de acuerdo con Clarisa, no es posible elaborar una nueva norma jurídica si no tiene una perspectiva de género. Es fundamental una norma jurídica que hable de derechos sexuales y reproductivos, que hable de los derechos LGBTI+. La Constitución del ochenta es totalmente masculinizada, habla continuamente del hombre y no hay ninguna referencia a las mujeres, así que la perspectiva de género tiene que estar, sin duda.

Creo que hoy no lo hemos dicho, pero nos ha violentado mucho ver a [Joaquín] Lavín hablar de socialdemocracia y a [Pablo] Longueira hablar desde su ostracismo, ha sido violento ver a Longueira hablar de apoyar el Apruebo. Eso amerita una revisión, porque el fascismo y el neofascismo van a tratar de sabotear el plebiscito y van a querer poner a sus constituyentes a redactar la nueva Constitución. Hay un elemento importante, que es la unidad, no hemos hablado de la unidad. A mí me preguntan por la unidad y creo que hay una falsa dicotomía, una suerte de división entre lo político y lo social, en circunstancias de que los movimientos sociales son tremendamente políticos, lo que instalan son demandas políticas porque requieren de cambios estructurales políticos: recuperar la educación como un derecho, la salud, la libertad de elegir prestadores de la salud. Esa cuña que han venido a instalar es una falsa dicotomía y creo que es necesario hablar de unidad política y unidad programática, hay que dotar de contenido el Apruebo, no basta con ir a votar, hay que hablar de cuáles van a ser los derechos sociales que se van a instalar en la discusión sobre la nueva norma jurídica, cuál va ser el rol del Estado. ¿Vamos a hablar de modelo? ¿Qué tipo de modelo de desarrollo económico, cultural, social, ambiental queremos? No es suficiente ir a votar, aprobar, hay que poner al centro el rol y la participación de las comunidades.

Carlos me ha escuchado decirlo: la pandemia no es culpa de los murciélagos, es el resultado de la destrucción de los ecosistemas y de los servicios ecológicos que brindan la biodiversidad, del avance de los monocultivos, de la destrucción de los recursos naturales y la fauna nativa. Por tanto, la pandemia pone al centro de la discusión la impropia relación del hombre con la naturaleza en el proceso de producción de bienes materiales y espirituales. Esa reflexión nos debe conminar a ver de qué manera nos relacionamos con la naturaleza, quiénes van a encarar esa norma jurídica de asignarle derechos a la naturaleza y no considerarla como una fuente ilimitada de recursos en la perspectiva de seguir profundizando este modelo exportador. Este nuevo paradigma es un nuevo contrato entre los seres humanos y la naturaleza.

Jennifer Abate: muchas gracias, Rodrigo. Diputada Camila Vallejo, palabras al cierre. 
Camila Vallejo: he dicho en las conversaciones dentro del partido que nosotros tenemos una contradicción, que es neoliberalismo versus democracia. Creemos que el neoliberalismo no garantiza la democracia, pero agregaría que el patriarcado entra en contradicción con la democracia. Lo que ha promovido el feminismo es superar todas estas estructuras de opresión, discriminación, donde algunos son superiores a otros. Es difícil concebir una sociedad realmente democrática, radicalmente democrática con un sistema patriarcal como el que tenemos; el patriarcado ha estado desde antes que el neoliberalismo.

Es un desafío tremendo y hay que pensarlo desde nuestras estructuras económicas, culturales, y eso tiene que ser con unidad. Dejando de lado la posible candidatura del compañero [Daniel] Jadue, que es comunista, tenemos que sentarnos a conversar sobre el programa; podemos dar un salto cualitativo y cuantitativo y espero que así sea. Comparto la visión de Rodrigo: si bien los partidos no somos me voy a poner en el mismo saco que los otros partidos aunque sienta que tenemos enormes y profundas diferencias, pero no voy a entrar en esa discusión ahora- lo mismo que éramos antes de la UP y que fuimos en la UP, creo que somos necesarios en este proceso, no suplantando a las organizaciones y lo que está sucediendo en los territorios, pero si no estamos, si no logramos esa unidad, nos vamos a dar un tremendo disparo en el pie y vamos a desaprovechar la oportunidad histórica que tenemos de generar una mejor correlación de fuerzas para la constituyente, para las municipales, para las elecciones parlamentarias, para los gobiernos regionales. $\mathrm{El}$ que piense que esto no es fundamental está totalmente perdido y creo que ni siquiera el movimiento social cree eso. El mandato es unidad y ponerse a discutir de programas y proyectos estratégicos con los que podamos coincidir profundamente.

Jennifer Abate: muchas gracias, diputada Camila Vallejo. Así terminamos este ciclo en homenaje a los cincuenta años del triunfo de Salvador Allende y del gobierno de la Unidad Popular. Muchas gracias. 